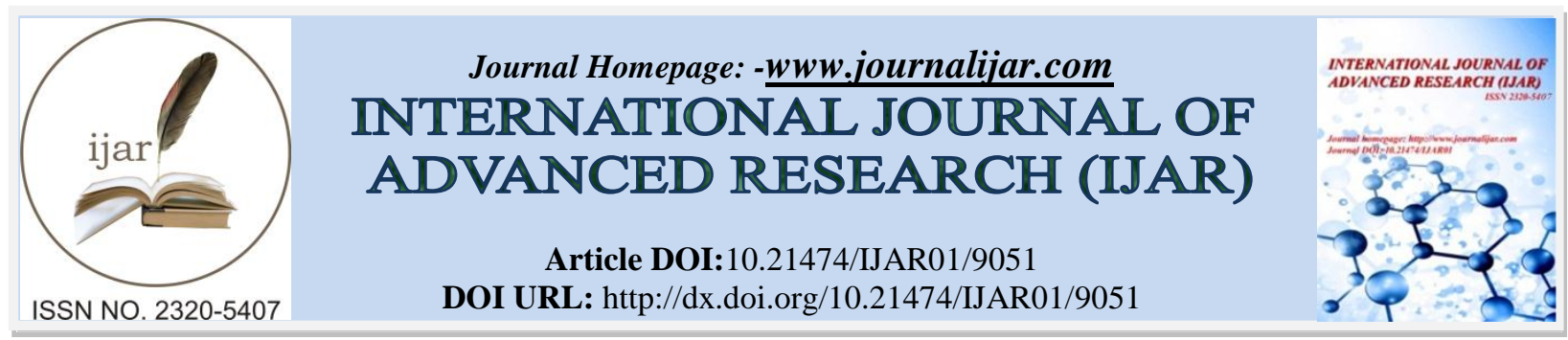

RESEARCH ARTICLE

\title{
AN APPLICATION OF ESTIMATING CAPABILITY INDICES FOR FATIGUE LIFE DISTRIBUTION.
}

\author{
Suboohi Safdar ${ }^{1}$, Ejaz Ahmed $^{2}$ and Arfa Maqsood ${ }^{1}$ \\ 1. Assistant Professor, Department of Statistics, University of Karachi. \\ 2. Dean, Computer Science, College of Computer Science \& Information Systems, Karachi Institute of Business \\ Management Korangi Creek.
}

\section{Manuscript Info}

Manuscript History

Received: 12 March 2019

Final Accepted: 14 April 2019

Published: May 2019

Key words:-

Capability Indices, Fatigue Life Model,

Non normality, Skewed Distribution,

Statistical Process control.

\begin{abstract}
There are variety of statistical distributions which cover most of the problem in reliability and time to event analysis. Birnbaum Saunders's distribution popularly named as Fatigue Life model is commonly and extensively applied for those quality characteristics of measurements which are associated with high occurrences. In this paper an applicative example is illustrated for earlier presented data sets that exhibiting Fatigue measurements constituted by Fatigue failure time of 3034 aluminum coupons oscillated at 18 cycles per second under 3 different stress levels with the fact that varying stress level producing number of failures which make the process out of control. So an algorithm is defined to first transform fatigue measurements to standard normal, make the process statistically controlled and estimate capability indices for measurements exhibit Fatigue distribution. An algorithm is made in R-console.
\end{abstract}

Copy Right, IJAR, 2019,. All rights reserved.

\section{Introduction:-}

In statistics we have variety of distributions which cover time to failure analysis in different scenario but these distributions have lack to specify the failures due to fatigue and a family of distribution is needed which specify the monotonic failure rates which others do not. Birnbaum-Saunders's (1969) derived comparatively flexible distribution from a phenomenon of physical fatigue where failures are attributed by crack growth. This probabilistic model thereafter named as Fatigue Life Model is designed for failure occurrence as a result of shock or crack accumulation due to over stress and used to expect life time of failures.

Process capability indices allows quantifying how well a process can produce acceptable product with the prediction of model adequacy that meet certain specification(s) and quality requirement(s) preset by the product designer. The aim of process capability analysis is to estimate, monitor, and possibly reduce variability in production or manufacturing processes. Measuring process capability yields huge cost savings by eliminating non-value added activities, reducing scrap, rework and creating satisfied customers. The challenge in today's competitive market is to be on the leading edge of producing high quality product at minimum costs. Continuously monitoring the process quality through these process capability indices assure that specifications supplying information for product design and process quality improvement provide the basis for reducing the cost and product defectives see Pan and Wu (1997). The use of PCIs can be more constructive once the bias and variability of the process is determined and understood. A process may be in statistical control, but not capable of meeting specifications if; process is off-center

Corresponding Author:-Suboohi Safdar.

Address:-Assistant Professor, Department of Statistics, University of Karachi. 
from nominal value (Bias); process variability is too large relative to specifications (Variation) and process is both off-center and has large variation (Bias and Variation). Numerous work have been reported to estimate PCIs considering bias and variation for normal and non-normal processes see for details Juran (1974), Kane (1986), Chan et al. (1988), Boyles (1991), and Pearn et al. (1992) and for non-normal process see Gunter (1989), Boyles (1994), Zwick (1995) among many others. Ahmed and Safdar (2010), (2014), (2019) worked on estimating capability indices for non-normal process under varied distributional condition. Safdar et al. [14] also noted that no straightforward algorithm is reported to estimate capability indices for those processes whose measurements are due to stress and reveal a high skewed curve and proposed procedure to estimate PCIs based on 101 Fatigue measurements of an earlier presented data set by Birnbaum and Saunders's (1969)

In this paper capability indices are estimated for three data sets (Earlier presented by Birnbaum and Saunders's (1969) named as psi21, psi26 and psi31 constituted by Fatigue life (T) of N=304 6061-T6 aluminum coupons oscillated at 18 cycles per second (cps) under 3 levels and exposed to a pressure with maximum stress of 21,000 pounds per square inch (psi) on 101, 26,000psi on 102 and 31,000 psi on 101 specimens. psi pounds per square inch. For data sets see APPENDIX I.

\section{Fatigue Life Model:}

Birnbaum-Saunders's distribution (1969) is popularly known as fatigue life distribution whose density function is $\mathrm{f}(\mathrm{t} ; \alpha, \beta)=\frac{1}{2 \alpha \beta}\left(\frac{\mathrm{t}}{\beta}\right)^{-1 / 2}\left[1+\left(\frac{\mathrm{t}}{\beta}\right)^{-1}\right] \times \frac{1}{\sqrt{2 \pi}} \operatorname{Exp}\left[-\frac{1}{2 \alpha^{2}}\left[\left(\frac{\mathrm{t}}{\beta}\right)^{-1 / 2}-\left(\frac{\mathrm{t}}{\beta}\right)^{1 / 2}\right]^{2}\right] ; \mathrm{t}>0, \alpha \beta>0$. Here $\alpha$ and $\beta$ are shape and scale parameter respectively.

For details see Seeger (1990), Smith (1985) and Stephens et al. (2001) and Vilca-Labra and Leiva (2006).

Safdar et al.(2019) transformed Fatigue density function to standard normal density function using a well-known transformation for $Z=\frac{(t / \beta)^{\frac{1}{2}}-(t / \beta)^{-\frac{1}{2}}}{\alpha}$ such that, $f(t) \cong f(z)=\frac{1}{\sqrt{2 \pi}} e^{-\frac{1}{2} z^{2}}$ and estimate capability indices for transformed fatigue measurement using developed PCIs for Normal processes.

\section{Process Capability Indices:}

For four basic PCIs $\mathrm{C}_{\mathrm{p}}, C_{\mathrm{pk}}, C_{\mathrm{pm}}, \mathrm{C}_{\mathrm{pmk}}$ Vannman 1995 proposed a superstructure as under;

$$
\mathrm{C}_{\mathrm{p}}(\mathrm{u}, \mathrm{v})=\frac{\mathrm{d}-\mathrm{u}|\mu-\mathrm{m}|}{3 \sqrt{\sigma^{2}+\mathrm{v}(\mu-\mathrm{T})^{2}}} u, v \geq 0
$$

Where

$$
\mathrm{C}_{\mathrm{p}}(0,0)=\mathrm{C}_{\mathrm{p}}, \mathrm{C}_{\mathrm{p}}(1,0)=\mathrm{C}_{\mathrm{pk}}, \mathrm{C}_{\mathrm{p}}(0,1)=\mathrm{C}_{\mathrm{pm}} \mathrm{C}_{\mathrm{p}}(1,1)=\mathrm{C}_{\mathrm{pmk}}
$$

$100(1-\alpha) \%$ Confidence interval for $\mathrm{C}_{\mathrm{p}}, C_{\mathrm{pk}}, C_{\mathrm{pm}}, \mathrm{C}_{\mathrm{pmk}}$ are

$$
\begin{gathered}
\left(\frac{\chi_{\mathrm{n}-1, \alpha / 2}}{(\mathrm{n}-1)^{\frac{1}{2}}} \hat{\mathrm{C}}_{\mathrm{p}}, \frac{\chi_{\mathrm{n}-1,1-\alpha / 2}}{(\mathrm{n}-1)^{\frac{1}{2}}} \hat{\mathrm{C}}_{\mathrm{p}}\right) \\
\hat{\mathrm{C}}_{\mathrm{pk}}\left[\frac{1 \pm \mathrm{z}_{1-\alpha / 2}}{\sqrt{2(\mathrm{n}-1)}]}\right. \\
\left(\frac{\chi_{\mathrm{n}, \alpha / 2}}{\sqrt{\mathrm{n}}} \widetilde{\mathrm{C}}_{\mathrm{pm}}, \frac{\chi_{\mathrm{n}, 1-\alpha / 2}}{\sqrt{\mathrm{n}}} \widetilde{\mathrm{C}}_{\mathrm{pm}}\right)
\end{gathered}
$$




$$
\hat{\mathrm{C}}_{\mathrm{pmk}} \mp z_{\alpha / 2} \frac{\hat{\sigma}_{p m k}}{\sqrt{n}}
$$

For details see Kotz and Johnson (1992), Nagata and Nagahata (1992), (1993), Boyles (1991), Subbaiah (1991) Patnaik (1949) and Chen and Hsu (1995).

\section{Method for Estimate PCIs for Fatigue Life Model:}

1. An algorithm is made to estimate PCIs using fatigue model in R-console and analysis is followed with packages $g b s$ and $V G A M$ in R-3.0.3.

2. Choose data set whose measurements come from two parameter Fatigue distribution and estimate $(\hat{\alpha}, \hat{\beta})$ based on maximum likelihood estimation MLE procedure.

3. From the estimated parameters simulate Fatigue samples " $\mathrm{t}$ " of sizes $\mathrm{n}=100,200,500$ and 1000 . Transformed Fatigue samples along with preset specification limits (LSL, USL) to standard normal varaite "Z".

4. Assess normality assumption by ShapiroWilk normality test for each simulated $(\mathrm{t})$ and transformed sample (z) to check normality assumptions.

5. Construct $\bar{X}-R$ control chart for each transformed sample with subgroup size of 10 to check that the transformed process is in statistical control. The program is designed so that it exclude those samples which are beyond the control limits.

6. Estimate PCIs and construct 95\% confidence intervals of each PCIs using Equation (1) to (5) for each transformed Fatigue Sample.

Data Sets for Illustration PCIs for Fatigue Life Model:

For the data sets (see APPENDIX I), the preset specification limits and MLE estimates of each data sets are summarized in Table 1. Figure 1 displays the density curves for three data sets.

Table 1:-Preset Limits \& MLE Parameters of psi21, psi26, psi31

\begin{tabular}{|c|c|c|c|c|c|}
\hline Data Sets & Size & LSL & USL & $\alpha$ & $\beta$ \\
\hline psi21 & 101 & 415 & 2417 & 0.3101 & 1336.377 \\
\hline psi26 & 102 & 240 & 560 & 0.1614 & 392.76 \\
\hline psi31 & 101 & 64 & 202 & 0.1704 & 131.82 \\
\hline
\end{tabular}
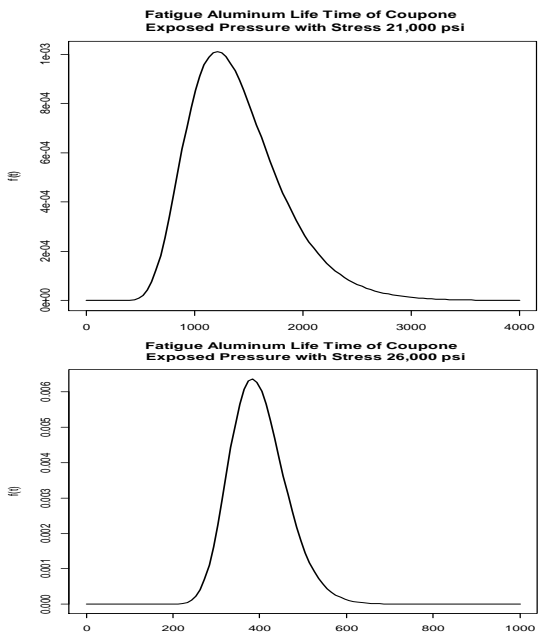


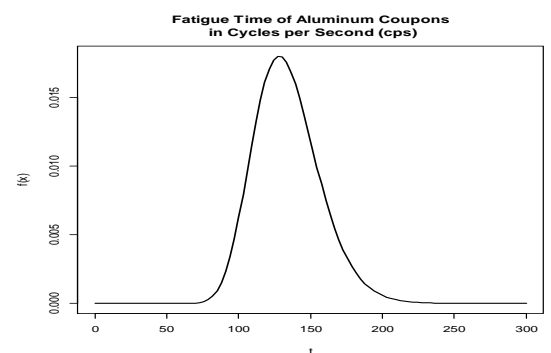

Fig 1:-Density Curves of Data Sets psi21, psi26, psi31

Before estimating capability indices the Shapiro-Wilk normality test is performed for each Fatigue and transformed samples for three data sets psi21, psi26 and psi31. See Table 2.

Table 2:-Shapiro-Wilk Normality Test for psi21, psi26, psi31

\begin{tabular}{|c|c|c|c|c|c|c|c|}
\hline \multirow{2}{*}{$\mathbf{n}$} & Data Sets & \multicolumn{2}{|c|}{$p s i 21$} & \multicolumn{2}{c|}{ psi26 } & \multicolumn{2}{c|}{ psi31 } \\
\cline { 2 - 8 } & Samples & SW-Test & P-value & SW-Test & P-value & SW-Test & P-value \\
\hline \multirow{2}{*}{100} & $\mathrm{t}$ & 0.990 & 0.669 & 0.960 & 0.004 & 0.980 & 0.133 \\
\cline { 2 - 8 } & $\mathrm{y}$ & 0.988 & 0.482 & 0.991 & 0.741 & 0.994 & 0.935 \\
\hline \multirow{2}{*}{200} & $\mathrm{t}$ & 0.990 & 0.164 & 0.966 & 0.000 & 0.960 & 0.000 \\
\cline { 2 - 8 } & $\mathrm{y}$ & 0.995 & 0.808 & 0.989 & 0.146 & 0.991 & 0.230 \\
\hline \multirow{2}{5}{500} & $\mathrm{t}$ & 0.995 & 0.119 & 0.959 & 0.000 & 0.981 & 0.000 \\
\cline { 2 - 8 } & $\mathrm{y}$ & 0.995 & 0.116 & 0.997 & 0.538 & 0.998 & 0.864 \\
\hline \multirow{2}{*}{1000} & $\mathrm{t}$ & 0.992 & 0.000 & 0.961 & 0.000 & 0.982 & 0.000 \\
\cline { 2 - 7 } & $\mathrm{y}$ & 0.998 & 0.211 & 0.999 & 0.697 & 0.998 & 0.476 \\
\hline
\end{tabular}

Table 2 shows that transformed Fatigue samples exhibiting Normal process and allow to obtain point and interval PCIs estimates using Equation (1) to (5) for each simulated transformed sample for three data sets psi21, psi26, psi31.

Table 3:-Point \& Interval Estimates of PCIs for Transformed Samples psi21, psi26, psi31

\begin{tabular}{|c|c|c|c|c|c|c|c|c|c|}
\hline Data Sets & $\mathbf{n}$ & $\mathbf{C}_{\mathrm{p}}$ & CI of $C_{p}$ & $C_{p k}$ & CI of $\mathbf{C}_{\mathrm{pk}}$ & $\mathrm{C}_{\mathrm{pm}}$ & CI of $\mathbf{C}_{\mathrm{pm}}$ & $C_{p m k}$ & CI of $C_{p m k}$ \\
\hline \multirow[t]{8}{*}{ psi21 } & 100 & 0.986 & $(0.809,1.169)$ & 0.605 & $(0.465,0.745)$ & 0.649 & $(0.533,0.769)$ & 0.398 & $(0.339,0.458)$ \\
\hline & 190 & 1.035 & $(0.899,1.173)$ & 0.694 & $(0.583,0.805)$ & 0.723 & $(0.629,0.819)$ & 0.485 & $(0.436,0.533)$ \\
\hline & 500 & 1.017 & $(0.934,1.100)$ & 0.631 & $(0.567,0.696)$ & 0.665 & $(0.611,0.72)$ & 0.413 & $(0.385,0.441)$ \\
\hline & 1000 & 1.007 & $(0.950,1.066)$ & 0.64 & $(0.594,0.685)$ & 0.677 & $(0.638,0.716)$ & 0.43 & $(0.409,0.450)$ \\
\hline & 100 & 0.903 & $(0.777,1.028)$ & 0.767 & $(0.642,0.892)$ & 0.836 & $(0.720,0.952)$ & 0.71 & $(0.642,0.778)$ \\
\hline & 190 & 0.876 & $(0.790,0.962)$ & 0.75 & $(0.663,0.836)$ & 0.819 & $(0.739,0.899)$ & 0.701 & $(0.653,0.749)$ \\
\hline & 500 & 0.878 & $(0.823,0.932)$ & 0.733 & $(0.679,0.787)$ & 0.805 & $(0.755,0.855)$ & 0.673 & $(0.644,0.702)$ \\
\hline & 1000 & 0.879 & $(0.841,0.972)$ & 0.737 & $(0.699,0.776)$ & 0.809 & $(0.774,0.844)$ & 0.679 & $(0.658,0.699)$ \\
\hline \multirow[t]{4}{*}{ psi31 } & 100 & 1.252 & $(1.078,1.426)$ & 0.889 & $(0.749,1.029)$ & 0.846 & $(0.729,0.963)$ & 0.601 & $(0.540,0.662)$ \\
\hline & 200 & 1.212 & $(1.093,1.331)$ & 0.895 & $(0.796,0.994)$ & 0.879 & $(0.792,0.965)$ & 0.649 & $(0.602,0.696)$ \\
\hline & 500 & 1.175 & $(1.102,1.203)$ & 0.853 & $(0.793,0.914)$ & 0.845 & $(0.793,0.898)$ & 0.614 & $(0.586,0.642)$ \\
\hline & 1000 & 1.153 & $(1.203,0.801)$ & 0.843 & $(0.801,0.885)$ & 0.845 & $(0.808,0.882)$ & 0.618 & $(0.598,0.638)$ \\
\hline
\end{tabular}

Table 3 summarized the results of point and interval PCIs estimates assuming normal process of transformed fatigue samples for each data set and for each sample.

\section{Conclusion and Recommendation:-}

A statistical procedure to estimate capability indices for BS distribution is implemented on three Birnbaum Saunders data sets exposed under three different stress levels. The PCIs along with their confidence intervals are estimated for transformed fatigue model and it is noted that each confidence interval contains the respective point estimate for each size of the sample.

This illustration allow quality practitioners and design producers who are working for Fatigue measurements to obtain capability indices for Fatigue processes along with making the process in statistical control. 


\section{References:-}

1. Birnbaum, Z. W. and Saunders, S. C. (1969) Estimation for a Family of Life Distributions with Applications to Fatigue. Journal of Applied Probability, 6, 328-347.

2. Pan, J. N, Wu S. L. (1997) Process Capability Analysis for Non-normal Relay Test Data. Microelectronics and Reliability, 37:421

3. Juran, J.M. (1974) Juran's Quality Control Handbook. 3rd Edition. McGraw-Hill, New York.

4. Kane, V.E. (1986) Process Capability Indices. Journal of Quality Technology, 18, 41-52.

5. Chan, L.K., Cheng, S.W. and Spiring, F.A. (1988). A New Measure of Process Capability: Cpm. Journal of Quality Technology, 20, 162-175.

6. Boyles, R. A. (1991). The Taguchi Capability Index. Journal of Quality Technology, 23, 107-126.

7. Pearn, W.L., Kotz, S. and Johnson, N.L. (1992) Distributional and Inferential Properties of Process Capability Indices. Journal of Quality Technology, 24, 216 -231.

8. Gunter, B.H. (1989). The Use and Abuse of Cpk. Quality Progress, 22, 108-109.

9. Boyles, R.A. (1994) Process Capability with Asymmetric Tolerance. Communications in Statistics: Simulations and Computation, 23, 615-643. http://dx.doi.org/10.1080/0361091940881319

10. Zwick, D. (1995) A Hybrid Method for Fitting Distributions to Data and It Use in Computing Process Capability Indices. Quality Engineering, 7, 601-613. http://dx.doi.org/10.1080/08982119508918806

11. Ahmed. E and Safdar. S, (2010) Process Capability Indices for on-Normal Data, Pakistan Business Review July 234-243

12. Safdar, S. and Ahmed, E. (2014) Process Capability Indices for Shape Parameter of Weibull Distribution, Open Journal of Statistics, 4, 207-219. http://dx.doi.org/10.4236/ojs.2014.43020

13. Suboohi Safdar, Ejaz Ahmed, Tehseen Ahmed and Arfa Maqsood International Journal of Advance Computer Science and Applications Vol 10, 3, 2019

14. Suboohi Safdar, Ejaz Ahmed and Arfa Maqsood (2019) Advanced and Applications in statistics (Accepted)

15. Baumel, Jr. and T. Seeger (1990) Materials data for cyclic loading, supplement 1. Elsevier ISBN 978-0-44488603-3.

16. N.A. Fleck, C.S. Shin, and R.A. Smith, (1985) Fatigue Crack Growth under Compressive Loading. Engineering Fracture Mechanics, 21(1) 173-185

17. Stephens, Ralph I.; Fuchs, Henry O. (2001) Metal Fatigue in Engineering (Second edition John Wiley \& Sons, Inc. p. 69

18. VannVilca-Labra and V. Leiva (2006) A New Fatigue Life Model based on the Family of Skew-Elliptical Distributions. Communications in Statistics: Theory and Methods, 35(2):1-16.

19. Vannman K. (1995) A Unified Approach to Capability Indices. Statistica Sinica, 5, 805-820.

20. Pearn, W. L, Kotz, S and Johnson, N. L. (1992) Distributional and Inferential Properties of Process Capability Indices. Journal of Quality Technology, 24, 216-231.

21. Nagata, Y. and Nagahata, H. (1992) Approximate Formulas for the Confidence Intervals of Process Capability Indices. Reports of Statistical Application Research 39:15-29

22. Nagata Y, Nagahata H. (1993) Approximation Formulas for the Confidence Intervals of Process Capability Indices. Technical Report Okayama University, Japan

23. Boyles, R. A. (1991). The Taguchi Capability Index. Journal of Quality Technology, 23, 107-126.

24. Subbaiah, P. and Taam, W. (1991) Inference on the Capability Index Cpm, MS, Dept. Math. Sci., Oakland University, Rochester, Minnesota

25. Patnaik, P. B. (19490 The Non-Central $\chi^{2}$ - and F Distributions and their Applications, Biometrika, 36, 202332

26. Chen, S. M. and Hsu, N. F. (1995). The Asymptotic Distribution of the Process Capability Index Cpmk. Communications in Statistics: Theory and Methods, 24(5), 1279-1291 
ISSN: 2320-5407

Int. J. Adv. Res. 7(5), 398-404

\begin{tabular}{|c|c|c|c|c|c|c|c|c|c|c|}
\hline \multirow[t]{11}{*}{ Psi21 } & 370 & 706 & 716 & 746 & 785 & 797 & 844 & 855 & 858 & 886 \\
\hline & 886 & 930 & 960 & 988 & 999 & 1115 & 1120 & 1134 & 1140 & 1199 \\
\hline & 1115 & 1120 & 1134 & 1140 & 1199 & 1115 & 1120 & 1134 & 1140 & 1199 \\
\hline & 1200 & 1200 & 1203 & 1222 & 1235 & 1238 & 1252 & 1258 & 1262 & 1269 \\
\hline & 1270 & 1290 & 1293 & 1300 & 1310 & 1313 & 1315 & 1330 & 1355 & 1390 \\
\hline & 1416 & 1419 & 1420 & 1420 & 1450 & 1452 & 1475 & 1478 & 1481 & 1485 \\
\hline & 1502 & 1505 & 1513 & 1522 & 1522 & 1530 & 1540 & 1560 & 1567 & 1578 \\
\hline & 1594 & 1602 & 1604 & 1608 & 1630 & 1642 & 1674 & 1730 & 1750 & 1750 \\
\hline & 1763 & 1768 & 1781 & 1782 & 1792 & 1820 & 1868 & 1881 & 1890 & 1893 \\
\hline & 1895 & 1910 & 1923 & 1924 & 1945 & 2023 & 2100 & 2130 & 2215 & 2268 \\
\hline & 2440 & & & & & & & & & \\
\hline \multirow[t]{11}{*}{ psi26 } & 233 & 258 & 268 & 276 & 290 & 310 & 312 & 315 & 318 & 321 \\
\hline & 321 & 329 & 335 & 336 & 338 & 338 & 342 & 342 & 342 & 344 \\
\hline & 349 & 350 & 350 & 351 & 351 & 352 & 352 & 356 & 358 & 358 \\
\hline & 360 & 362 & 363 & 366 & 367 & 370 & 370 & 372 & 372 & 374 \\
\hline & 375 & 376 & 379 & 379 & 380 & 382 & 389 & 389 & 395 & 396 \\
\hline & 400 & 400 & 400 & 403 & 404 & 406 & 408 & 408 & 410 & 412 \\
\hline & 414 & 416 & 416 & 416 & 420 & 422 & 423 & 426 & 428 & 432 \\
\hline & 432 & 433 & 433 & 437 & 438 & 439 & 439 & 443 & 445 & 445 \\
\hline & 452 & 456 & 456 & 460 & 464 & 466 & 468 & 470 & 470 & 473 \\
\hline & 474 & 476 & 476 & 486 & 488 & 489 & 490 & 491 & 503 & 517 \\
\hline & 540 & 560 & & & & & & & & \\
\hline \multirow[t]{11}{*}{ psi31 } & 70 & 90 & 96 & 97 & 99 & 100 & 103 & 104 & 104 & 105 \\
\hline & 107 & 108 & 108 & 108 & 109 & 109 & 112 & 112 & 113 & 114 \\
\hline & 114 & 114 & 116 & 119 & 120 & 120 & 120 & 121 & 121 & 123 \\
\hline & 124 & 124 & 124 & 124 & 124 & 128 & 128 & 129 & 129 & 130 \\
\hline & 130 & 130 & 131 & 131 & 131 & 131 & 131 & 132 & 132 & 132 \\
\hline & 133 & 134 & 134 & 134 & 134 & 134 & 136 & 136 & 137 & 138 \\
\hline & 138 & 138 & 139 & 139 & 141 & 141 & 142 & 142 & 142 & 142 \\
\hline & 142 & 142 & 144 & 144 & 145 & 146 & 148 & 148 & 149 & 151 \\
\hline & 151 & 152 & 155 & 156 & 157 & 157 & 157 & 157 & 158 & 159 \\
\hline & 162 & 163 & 163 & 164 & 166 & 166 & 168 & 170 & 174 & 196 \\
\hline & 212 & & & & & & & & & \\
\hline
\end{tabular}

